\title{
Análise comparativa da diversidade florística de dois núcleos de desertificação no semiárido nordestino.
}

Comparative analysis of the floristic diversity of the two core in the northeast semiarid.

\author{
SOUSA $^{1}$, A. K.O.; TRIGUEIRO ${ }^{2}$, E. R. C.; BEZERRA ${ }^{3}$, C. L. F; SOUSA ${ }^{4}$, S. C; \\ OLIVEIRA $^{5}$, V. P.V. \\ karoldsousa@gmail.com
}

\begin{abstract}
Resumo
O semiárido do nordeste brasileiro é compreendido pelo bioma caatinga, ocupando cerca de $844.453 \mathrm{Km}^{2}$ o equivalente a $11 \%$ do território nacional. Porém, é o bioma menos protegido do país, com $1,5 \%$ apenas. Atualmente cerca de $46 \%$ já sofreram com os avanços do desmatadmento, o que justifica grande parte das áreas susceptíveis à desertificação terem sido ocupadas originalmente por esse bioma. Partindo da necessidade de aprofundar os conhecimentos sobre as riquezas e suas vulnerabilidades para melhor preservá-lo, o presente artigo vem trazer como objetivo a análise comparativa da diversidade florística e sua relação com a degradação ambiental de dois núcleos de desertificação: a sub-bacia do riacho Cipó/Carrapateiras no município de TauáCeará e a sub-bacia do riacho Itacuruba/Tamanduá no município de Itacuruba em Pernambuco. A pesquisa teve como base os dados florísticos levantados por Trigueiro (2003), Gonçalves (2003) e Sousa (2014), além de visitas in lócus. Os resultados apontaram que os núcleos reúnem uma diversidade de 51 espécies e 19 famílias, sendo 38 espécies e 14 famílias no núcleo cearense e 23 espécies e 12 famílias para o núcleo pernambucano, com maior número de espécies nas planícies fluviais, e menor diversidade nas depressões sertanejas aplainadas e dissecadas.
\end{abstract}

Palavras-chave: Caatinga. Degradação ambiental. Sistemas ambientais.

\begin{abstract}
The brazilian northeastern semiarid region is understood by the caatinga biome, occupying about of $844,453 \mathrm{Km}^{2}$ the equivalent to $11 \%$ of the national territory. However, is the least protected of the biome, with $1.5 \%$ only. Currently about $46 \%$ have suffered with the advances of the deforestation, which explains much of the areas susceptible to desertification have been occupied by this biome. Starting from the need to deepen the knowledge about the riches and their vulnerabilities to better preserve it, the present article comes bring objective comparative analysis of the floristic diversity and its relationship with environmental degradation of two cores of desertification: the creek sub-basin Cipó/Carrapateiras in the municipality of Tauá-Ceará and the creek sub-basin Itacuruba/ Tamanduá in the municipality of Itacuruba in Pernambuco. The research was based on the floristic data collected by Trigueiro (2003), Gonçalves (2003) and Sousa (2014), in addition to visits in locus. The results showed that the nuclei together a diversity of 51 species and 19 families, and 38 species and 14 families at the core of Ceará and 23 species and 12 families to the core of Pernambuco, with the largest number of species in the river plains, and less diversity in the hinterland flattened depressions and dissected.
\end{abstract}

Keywords: Caatinga. Environmental degradation. Environmentals systems.

\section{INTRODUÇÃO}

A cobertura vegetal do semiárido do nordeste é compreendida pelo bioma caatinga, que conforme o Ministerio do Meio Ambiente (MMA, [201-]), ocupa cerca de $844.453 \mathrm{Km}^{2}$ o equivalente a $11 \%$ do território nacional. Porém, é o bioma menos protegido do país, apenas cerca de $1,5 \%$ está contemplado por unidades de proteção integral.

Por ser um bioma genuinamente brasileiro, os estudos ficam menos visados a níveis globais, e acabam portando, sendo limitados a áreas pontuais em torno das principais cidades da região. $\mathrm{O}$

\author{
${ }^{1}$ Ana Karolina de Oliveira Sousa, \\ ${ }^{2}$ Msc.Eliedir Ribeiro da Cunha Trigueiro, \\ ${ }^{3}$ Prof $^{\circ}$ Carlos Lineu Frota Bezerra, \\ ${ }^{4}$ Dr.Sebastião Cavalcante de Sousa, \\ ${ }^{5}$ Dra. Vládia Pinto Vidal de Oliveira. ${ }^{1,4,5}$ Departamento de Geografia $/{ }^{2}$ Seara da Ciência $/{ }^{3}$ Departamento de Biologia / Laboratório \\ de Pedologia Análise Ambiental e Desertificação - LAPED, Universidade Federal do Ceará -UFC, Fortaleza-CE, Brasil.
}


desconhecimento de sua biodiversidade favorece a disseminação da cultura da exploração, provocada pelo uso insustentável dos seus recursos naturais (LEAL; TABARELLI; SILVA, 2003).

Tais práticas com origens desde o período da colonização, se configuram nos diferentes usos e ocupações (pecuária extensiva, agricultura de subsistência, extrativismos vegetal) ocorridas de forma desequilibradas com as reais capacidades de suporte do ambiente, tendo a cobertura vegetal como um dos primeiros recursos explorados, haja vista a necessidade de sua retirada para a instalação das atividades agropecuárias.

Atualmente cerca de $46 \%$ da área de abrangência da caatinga já sofreu com o avanço do desmatamento, o que justifica os $62 \%$ das áreas susceptíveis à desertificação terem sido ocupadas originalmente por esse bioma (MMA, [201-]).

Cerca 27 milhões de pessoas vivem na área original da caatinga (MMA, [201-]). Daí a importância da preservação desses sistemas semiáridos, pois são deles que se retiram os recursos para o desenvolvimento socioeconômico da região.

Partindo da necessidade de aprofundar os conhecimentos sobre as riquezas e vulnerabilidades do bioma caatinga, o presente artigo vem destacar a realidade de dois núcleos de desertificação, os quais apresentam indicativos de degradação através da perda da diversidade florísticas nos sistemas ambientais. O primeiro situado a oeste do estado Ceará no Sertão dos Inhamuns, aqui compreendido pela sub-bacia do riacho Cipó/Carrapateiras, localizado entre as coordenadas de $40^{\circ} 00^{\prime} 41,4^{\prime \prime} \mathrm{W}$ e $5^{\circ} 23^{\prime} 49,0$ " $\mathrm{S}$ e $40^{\circ} 14^{\prime} 03.5^{\prime} \mathrm{W}$ e $5^{\circ} 47^{\prime} 18,7^{\prime} \mathrm{S}$ ao norte do município de Tauá, com área equivalente a $546.687 \mathrm{~km}^{2}$. E o segundo, que se encontra no Sertão Central do estado de Pernambuco no município de Itacuruba. Corresponde a sub-bacia do riacho Itacuruba /Tamanduá, um afluente do Rio São Francisco. Está localizado entre as coordenadas geográficas $08^{\circ} 43^{\prime} 47,5^{\prime}$ S e $08^{\circ} 48^{\prime} 07,8^{\prime \prime} \mathrm{S}$ e $38^{\circ} 40^{\prime} 54,3^{\prime}$ W e $38^{\circ} 43^{\prime} 38,1^{\prime}$ "W apresentando uma área de $175,066 \mathrm{Km}^{2}$ (SOUSA, 2014).

$\mathrm{O}$ artigo objetiva analisar a diversidade florística de ambos os núcleos de desertificação a partir da comparação de riquezas de espécies e suas relações com a degradação ambiental. Com base nessas análises, busca-se obter conhecimentos mais consistentes sobre a atual composição florística dessas áreas degradadas, para que tais conhecimentos possam posteriormente subsidiar intervenções menos degradantes de convivência com o semiárido.

\section{METODOLOGIA}

Os estudos foram desenvolvidos com base em análises comparativas de dados florísticos levantados por Trigueiro (2003), Gonçalves (2003) e Sousa (2014). Trabalhos os quais estão vinculados ao projeto de pesquisas "Análise comparativa de indicadores geobiofísicos de três 
núcleos de desertificação e da dinâmica das paisagens no semiárido do nordeste brasileiro" referente ao edital Universal MCTI/CNPq No 14/2013, e que tem como instituição execultora a Universidade Federal do Ceará - UFC.

Como recorte espacial de análise foram considerados os sistemas ambientais compatíveis com as áreas onde ocorreram os levantamentos florísticos em cada um dos núcleos: a depressão sertaneja aplainada, depressão sertaneja dissecadas, cristas residuais e as planícies fluviais.

A contagem do número de espécies foi realizada para cada sistema ambiental e a somatória do número de espécies. Utilizou- se a somatória como expressão da diversidade florística, e posteriormente comparadas os respectivos valores.

A pesquisa encontra-se dividida em duas fases: i) levantamento bibliográfico e geocartográfico (tese, dissertação, artigo, mapas) para a realização do levantamento das espécies vegetacionais e para a caracterização dos sistemas ambientais ii) e atividades de campo, onde foram realizadas análises dos processos de degradação/desertificação e suas influências na dinâmica atual da cobertura vegetal.

\section{RESULTADOS E DISCUSSÃO}

Os estados do Ceará e Pernambuco possuem respectivamente cerca de $92 \%$ e 79,96\% de seus territórios sob a influência da semiaridez (CEARÁ, 2010; PERNAMBUCO, 2009), aspecto este que dar condições climáticas favoráveis ao desenvolvimento natural da caatinga, cuja se caracteriza por uma vegetação xerófila e caducifólia dado as restrições hídricas durante a maior parte do ano, com poucas espécies perenifólias.

A cobertura vegetal se traduz em um biodicador de degradação, uma vez que qualquer alteração nos procesos de fluxos de matéria e energia dentro do sistema, acarreta influências sob a vegetação, expressadas muitas das vezes pelo nanonimo dos indivíduos associado a diminuição da biodiversidade. As mudanças por mínimas que seja - alteração a composição físíco-química dos solos, quantidade de úmidade e luz - afeta diretamente no desenvolvimento e na relação de competição entre as espécies.

Quando se trata da análise da diversidade florística em núcleos de desertificação - onde as condições naturais do meio encontram-se altamente alteradas - se deve imprecidivelmente levar em consideração essas observações.

Nesse contexto foi realizado a partir de dados secundários o levantamento florístico nos dois núcleos: o da sub-bacia Cipó/Carrapateiras, onde foram constatados 38 espécies e 14 famílias; e no de Itacuruba/Tamanduá com 23 espécies e 12 famílias. O quadro 1 e 2 traz a listagem geral das espécies para cada núcleo. 
Quadro1 - Listagem das espécies vegetacionais do núcleo de Cipó/Carrapateiras. Fonte: Trigueiro (2003); Gonçalves (2003). Adaptado pelos autores, 2016.

\begin{tabular}{|c|c|c|c|c|c|}
\hline Nome popular & Nome científico & Família & Nome popular & Nome científico & Família \\
\hline Ameixa & Ximenia americana Linn. & Olacaceae & $\begin{array}{l}\text { Imburana-de- } \\
\text { cheiro }\end{array}$ & $\begin{array}{l}\text { Torresa cearensis (Fr. All.) A. C. } \\
\text { Smith }\end{array}$ & Leguminosae \\
\hline Angico & $\begin{array}{c}\text { Anadenanthera colubrine (Vell.) } \\
\text { Brenan. }\end{array}$ & Leguminosae & Ingá & Inga sp. & Leguminosae \\
\hline Aroeira & Myracroduon urundeuva Fr.All. & Anacardiaceae & Mandacaru & Cereus jamacaru DC. & Cactaceae \\
\hline Burra leiteira & Sapium sp. & Euphorbiaceae & Maniçoba & Manihot sp. & Euphorbiaceae \\
\hline Canafístula & Cassia sp. & Leguminosae & Malva Preta & Sida micrantha St. Hil & Malvaceae \\
\hline Cardeiro & Cereus sp. & Cactaceae & Marmeleiro & Crotonson derianus Muell. & Euphorbiaceae \\
\hline Catingueira & Caesalpinia pyramidalis Tul. & Leguminosae & Mofumbo & Combretum leprosum Mart. & Combretaceae \\
\hline Caatinga Branca & Croton adenocalix Baill. & Euphorbiaceae & Mororó & Bauhinia fortificata Lin. & Leguminosae \\
\hline $\begin{array}{l}\text { Cipó de açoita } \\
\text { cavalo }\end{array}$ & Luehea sp. & Tiliaceae & Muquém & Albizia sp. & Leguminosae \\
\hline Cipó de cururei & Bauhinia sp. & Leguminosae & Pajeú & Triplaris sp. & Polygonaceae \\
\hline Favela & $\begin{array}{c}\text { Cnidosculus phylacanthus Pax. \& K. } \\
\text { Huf. }\end{array}$ & Cactaceae & Pau pedra & $\mathrm{X} s p$ & Leguminosae \\
\hline Facheiro & Cereus squamosus Guerke & Euphorbiaceae & Pau ferro & Caesalpinia ferrea Mart. & Leguminosae \\
\hline Feijão bravo & Capparis flexuosa $(\mathrm{L}$.) L. & Capparaceae & Pereiro & Aspidosperma pyrifolium Mart. & Apocynaceae \\
\hline João Mole & Guapira oposita Vell. & Nictaginaceae & Pinhão & Jatropha molissima (Pohl.) Baill. & Euphorbiaceae \\
\hline Juazeiro & Zizyphus joazeiro Mart. & Rhamnaceae & Quebra-faca & Cássia trachypus Mart. & Leguminosae \\
\hline Jucá & Caesalpinia ferrea Mart. & Leguminosae & Rompe gibão & Mimosa sp. & Leguminosae \\
\hline Jurema Branca & Pithecellobium diversifolium Benth & Leguminosae & Sabiá & Mimosa caesalpiniaefolia Benth. & Leguminosae \\
\hline Jurema preta & Mimosa hostilis Benth. & Leguminosae & Velame & Cróton $\mathrm{sp}$. & Euphorbiaceae \\
\hline $\begin{array}{c}\text { Imburana de } \\
\text { espinho }\end{array}$ & $\begin{array}{l}\text { Commiphora lepthafloeos (Mart.) } \\
\text { Gillet. }\end{array}$ & Burseraceae & Xique-xique & Pilosocereus gounellei Weber & Cactaceae \\
\hline
\end{tabular}

Quadro2 - Listagem das espécies vegetacionais do núcleo de Itacuruba/Tamanduá. Fonte: Sousa (2014). Adaptado pelos autores, 2016.

\begin{tabular}{|c|c|c|c|c|c|}
\hline Nome popular & Nome científico & Família & Nome popular & Nome científico & Família \\
\hline Angico & $\begin{array}{l}\text { Anadenanthera macrocarpa (Benth.) } \\
\text { Brenan. }\end{array}$ & Leguminosae & Mandacaru & Cereus jamacuru DC. & Cactáceae \\
\hline Algaroba & Prosopis juliflora (Sw) DC. & Leguminosae & Malva branca & Wissadula sp. & Malvaceae \\
\hline Aroeira & Myracroduon urundeuva Fr.All. & Anacardiaceae & Pereiro & Aspidosperma pyrifolium Mart. & Apocynaceae \\
\hline Bom nome & Maytenus rígida Mart. & Celastraceae & Pinhão-bravo & Jatropha molíssima (Pohl.) Baill & Euphorbiaceae \\
\hline Brauna & Schinopsis brasiliensis Engl. & Anacardiaceae & Quebra faca & Crotoncon duplicatus Kunth & Euphorbiaceae \\
\hline Catingueira & Caesalpinia pyramidalis Tul. & Leguminosae & Quipá & Opuntia inamoena $\mathrm{K}$. Shum & Cactáceae \\
\hline $\begin{array}{c}\text { Cipó de } \\
\text { vaqueiro }\end{array}$ & Davilla rugosa Poir.et St. Hill & Dilleniaceae & Rompe gibão & $\begin{array}{l}\text { Sideroxylon obtusifolium (Roem. } \\
\text { \&Schult.) Pennington }\end{array}$ & Sapotaceae \\
\hline Faveleira & $\begin{array}{l}\text { Cnidoscolus phyllacanthus (Muell. Arg.) } \\
\text { Pax\& K. Hoffm. }\end{array}$ & Euphorbiaceae & $\begin{array}{l}\text { Umburana-de- } \\
\text { cambão }\end{array}$ & Bursera leptophloeos Mart. & Burseraceae \\
\hline Folha-de-carne & Casearia sylvestris $\mathrm{Sw}$ & Flacourtiaceae & Umbuzeiro & Spondias tuberosa Arruda & Anacardiaceae \\
\hline Jucá & Caesalpina ferrea Mart. exTul. & Leguminosae & Velame & Croton campestri-St. Hilai & Euphorbiaceae \\
\hline $\begin{array}{l}\text { Jurema } \\
\text { branca }\end{array}$ & Pithecellobium diversifolium Benth & Leguminosae & Xique-xique & Pilocereus gounellei Weber. & Cactáceae \\
\hline Macambira & Bromelia laciniosa Mart. & Bromeliaceae & & & \\
\hline
\end{tabular}

De acordo com os quadros, podemos observar que a sub-bacia do riacho Cipó/Carrapateiras apresenta maior diversidade de espécie e família em comparado com a sub-bacia de Itacuruba/Tamanduá, revelando que, apesar das fortes intervenções presentes em seus sistemas ambientais a mesma ainda conserva uma menor degradação ambiental.

Dentre essas espécies (ver quadro 3), 27 destacam como presentes ao núcleo cearense: Ximenia americana Linn (Ameixa); Sapium sp. (Burra leiteira); Cassia sp. (Canafistula); Cereus sp. (Cardeiro); Croton adenocalix Baill. (Caatinga branca); Bauhinia sp. (Cipó de cururei); Cereus squamosus Guerke (Facheiro); Capparis flexuosa (L.) L. (Feijão bravo); Guapira oposita Vell. (João mole); Zizyphus joazeiro Mart. (Juazeiro); Mimosa hostilis Benth. (Jurema preta); 
Commiphora lepthafloeos (Mart.) Gillet. (Imburana de espinho); Torresa cearensis (Fr. All.) A. C. Smith (Imburana de cheiro); Inga sp. (Ingá), Manihot sp. (Maniçoba); Sida micrantha St. Hil (Malva preta); Crotonson derianus Muell. (Marmeleiro); Combretum leprosum Mart. (Mufumbo); Bauhinia fortificata Lin (Mororó); Albizia sp. (Muquém); Triplaris sp. (Pajeú), X sp (Pau pedra); Caesalpinia ferrea Mart. (Pau ferro); Cássia trachypus Mart. (Queba-faca); Mimosa sp. (Rompe Gibão); Mimosa caesalpiniaefolia Benth. (Sabiá); e Cróton sp. (Velame).

Destacam-se como presente ao núcleo pernabucano 13 espécies: Prosopis juliflora (Sw) DC. (Algaroba); Maytenus rígida Mart. (Bom nome), Schinopsis brasiliensis Engl. (Brauna); Davilla rugosa Poir.et St. Hill (Cipó de vaqueiro); Casearia sylvestris Sw (Folha-de-carne); Bromelia laciniosa Mart. (Macambira); Wissadula sp. (Malva branca); Crotoncon duplicatus Kunth (Quebrafaca **); Opuntia inamoena K. Shum (Quipá); Sideroxylon obtusifolium (Roem. \&Schult.) Pennington (Rompe-Gibão**); Bursera leptophloeos Mart. (Umburana-de -Cambão); Spondias tuberosa Arruda (Umbuzeiro); e Croton campestri-St. Hilai (Velame**).

As espécies comuns a ambos os núcleos são 10: Anadenanthera colubrina (Vell.) Brenan. (Angico); Myracroduon urundeuva Fr. All. (Aroeira); Caesalpinia pyramidalis Tul. (Catingueira); Cnidoscolus phyllacanthus (Muell. Arg.) Pax\& K. Hoffm. (Favela); Caesalpinia ferrea Mart. (Jucá); Pithecellobium diversifolium Benth. (Jurema branca); Cereus jamacaru DC. (Mandacaru); Aspidosperma pyrifolium Mart. (Pereiro); Jatropha molissima (Pohl.) Baill. (Pinhão-bravo *); e Pilosocereus gounellei Weber (Xique-xique).

Dessas, apenas três espécies existem em todos os sitemas ambientais de ambos os núcleos: a Caesalpinia pyramidalis Tul. (Catingueira), Cnidoscolus phyllacanthus (Muell. Arg.) Pax\& K. Hoffm. (Favela) e a Jatropha molissima (Pohl.) Baill. (Pinhão-bravo *)

No que se refere ao nível de família, no o núcleo cearense obteve-se um total de 7 presentes: Capparaceae, Combretaceae, Nictaginaceae, Olacaceae, Polygonaceae, Rhamnaceae e Tiliaceae. Para o núcleo pernambucano foram somente 5 famílias: Bromeliaceae, Celastraceae, Dilleniaceae, Flacourtiaceae e Sapotaceae. As famílias em comuns foram: Anacardiaceae, Apocynaceae, Burseraceae, Cactaceae, Euphorbiaceae, Leguminosae e Malvaceae.

Quadro 3 - Listagem geral de espécies para os dois núcleos de desertificação e sua distribuição nos sistemas ambientais. Fonte: Trigueiro (2003), Gonçalves (2003) e Sousa (2014). Adaptado pelos autores, 2016.

\begin{tabular}{|c|c|c|c|c|c|c|c|c|c|c|c|c|}
\hline Nome popular & Nome científico & Família & N1 & d.s.a & d.s.d & c.r & p.f & N2 & d.s.a & d.s.d & c.r & p.f \\
\hline Algaroba & Prosopis juliflora $(\mathrm{Sw}) \mathrm{DC}$. & Leguminosae & & & & & & $\mathrm{x}$ & $\mathrm{x}$ & & & \\
\hline Ameixa & Ximenia americana Linn. & Olacaceae & $\mathbf{x}$ & & & & $\mathbf{x}$ & & & & & \\
\hline Angico & Anadenanthera colubrina (Vell.) Brenan. & Leguminosae & $\mathbf{x}$ & $\mathbf{x}$ & $\mathbf{x}$ & $\mathbf{x}$ & $\mathbf{x}$ & $\mathbf{x}$ & & & $\mathbf{x}$ & \\
\hline Aroeira & Myracroduon urundeuva Fr.All. & Anacardiaceae & $\mathbf{x}$ & $\mathbf{x}$ & $\mathbf{x}$ & $\mathbf{x}$ & $\mathbf{x}$ & $\mathbf{x}$ & & & $\mathbf{x}$ & \\
\hline Bom nome & Maytenus rígida Mart. & Celastraceae & & & & & & $\mathbf{x}$ & $\mathbf{x}$ & & & $\mathbf{x}$ \\
\hline Brauna & Schinopsis brasiliensis Engl. & Anacardiaceae & & & & & & $\mathbf{x}$ & & & & $\mathbf{x}$ \\
\hline Burra leiteira & Sapium sp. & Euphorbiaceae & $\mathbf{x}$ & & & $\mathbf{x}$ & $\mathbf{x}$ & & & & & \\
\hline Canafístula & Cassia sp. & Leguminosae & $\mathbf{x}$ & & & & $\mathbf{x}$ & & & & & \\
\hline
\end{tabular}




\begin{tabular}{|c|c|c|c|c|c|c|c|c|c|c|c|c|}
\hline Cardeiro & Cereus sp. & Cactaceae & $\mathbf{x}$ & & & $\mathbf{x}$ & & & & & & \\
\hline Catingueira & Caesalpinia pyramidalis Tul. & Leguminosae & $\mathbf{x}$ & $\mathbf{x}$ & $\mathbf{x}$ & $\mathbf{x}$ & $\mathbf{x}$ & $\mathbf{x}$ & $\mathbf{x}$ & $\mathbf{x}$ & $\mathbf{x}$ & $\mathbf{x}$ \\
\hline Caatinga Branca & Croton adenocalix Baill. & Euphorbiaceae & $\mathbf{x}$ & & & & $\mathbf{x}$ & & & & & \\
\hline $\begin{array}{c}\text { Cipó de açoita } \\
\text { cavalo }\end{array}$ & Luehea sp. & Tiliaceae & $\mathbf{x}$ & & & & $\mathbf{x}$ & & & & & \\
\hline Cipó de cururei & Bauhinia sp. & Leguminosae & $\mathbf{x}$ & & & & $\mathbf{x}$ & & & & & \\
\hline Cipó de vaqueiro & Davilla rugosa Poir.et St. Hill & Dilleniaceae & & & & & & $\mathbf{x}$ & & $\mathbf{x}$ & & $\mathbf{x}$ \\
\hline Favela & $\begin{array}{l}\text { Cnidoscolus phyllacanthus (Muell. Arg.) } \\
\text { Pax\& K. Hoffm. }\end{array}$ & Euphorbiaceae & $\mathbf{x}$ & $\mathbf{x}$ & $\mathbf{x}$ & $\mathbf{x}$ & $\mathbf{x}$ & $\mathbf{x}$ & $\mathbf{x}$ & $\mathbf{x}$ & $\mathbf{x}$ & $\mathbf{x}$ \\
\hline Facheiro & Cereus squamosus Guerke & Euphorbiaceae & $\mathbf{x}$ & $\mathbf{x}$ & $\mathbf{x}$ & & $\mathbf{x}$ & & & & & \\
\hline Feijão bravo & Capparis flexuosa $(\mathrm{L}.) \mathrm{L}$. & Capparaceae & $\mathbf{x}$ & $\mathbf{x}$ & & & $\mathbf{x}$ & & & & & \\
\hline Folha-de-carne & Casearia sylvestris $\mathrm{Sw}$ & Flacourtiaceae & & & & & & $\mathbf{x}$ & & & & $\mathbf{x}$ \\
\hline João Mole & Guapira oposita Vell. & Nictaginaceae & $\mathbf{x}$ & & & $\mathbf{x}$ & $\mathbf{x}$ & & & & & \\
\hline Juazeiro & Zizyphus joazeiro Mart. & Rhamnaceae & $\mathbf{x}$ & & & & $\mathbf{x}$ & & & & & \\
\hline Jucá & Caesalpinia ferrea Mart. & Leguminosae & $\mathbf{x}$ & $\mathbf{x}$ & & & $\mathbf{x}$ & $\mathbf{x}$ & & & & $\mathbf{x}$ \\
\hline Jurema branca & Pithecellobium diversifolium Benth & Leguminosae & $\mathbf{x}$ & $\mathbf{x}$ & $\mathbf{x}$ & $\mathbf{x}$ & $\mathbf{x}$ & $\mathbf{x}$ & & & & $\mathbf{x}$ \\
\hline Jurema preta & Mimosa hostilis Benth. & Leguminosae & $\mathbf{x}$ & $\mathbf{x}$ & $\mathbf{x}$ & $\mathbf{x}$ & $\mathbf{x}$ & & & & & \\
\hline $\begin{array}{c}\text { Imburana de } \\
\text { espinho }\end{array}$ & Commiphora lepthafloeos (Mart.) Gillet. & Burseraceae & $\mathbf{x}$ & & & $\mathbf{x}$ & $\mathbf{x}$ & & & & & \\
\hline $\begin{array}{l}\text { Imburana-de- } \\
\text { cheiro }\end{array}$ & Torresa cearensis (Fr. All.) A. C. Smith & Leguminosae & $\mathbf{x}$ & & & & $\mathbf{x}$ & & & & & \\
\hline Ingá & Inga sp. & Leguminosae & $\mathbf{x}$ & & & & $\mathbf{x}$ & & & & & \\
\hline Macambira & Bromelia laciniosa Mart. & Bromeliaceae & & & & & & $\mathbf{x}$ & & & $\mathbf{x}$ & \\
\hline Mandacaru & Cereus jamacaru DC. & Cactaceae & $\mathbf{x}$ & $\mathbf{x}$ & $\mathbf{x}$ & $\mathbf{x}$ & $\mathbf{x}$ & $\mathbf{x}$ & & & $\mathbf{x}$ & \\
\hline Maniçoba & Manihot sp. & Euphorbiaceae & $\mathbf{x}$ & $\mathbf{x}$ & & & & & & & & \\
\hline Malva Preta & Sida micrantha St. Hil & Malvaceae & $\mathbf{x}$ & & & & $\mathbf{x}$ & & & & & \\
\hline Malva Branca & Wissadula sp. & Malvaceae & & & & & & $\mathbf{x}$ & & & & $\mathbf{x}$ \\
\hline Marmeleiro & Crotonson derianus Muell. & Euphorbiaceae & $\mathbf{x}$ & $\mathbf{x}$ & $\mathbf{x}$ & $\mathbf{x}$ & $\mathbf{x}$ & & & & & \\
\hline Mofumbo & Combretum leprosum Mart. & Combretaceae & $\mathbf{x}$ & $\mathbf{x}$ & $\mathbf{x}$ & $\mathbf{x}$ & $\mathbf{x}$ & & & & & \\
\hline Mororó & Bauhinia fortificata Lin. & Leguminosae & $\mathbf{x}$ & $\mathbf{x}$ & & $\mathbf{x}$ & $\mathbf{x}$ & & & & & \\
\hline Muquém & Albizia sp. & Leguminosae & $\mathbf{x}$ & & & & $\mathbf{x}$ & & & & & \\
\hline Pajeú & Triplaris sp. & Polygonaceae & $\mathbf{x}$ & & & & $\mathbf{x}$ & & & & & \\
\hline Pau pedra & $X s p$ & Leguminosae & $\mathbf{x}$ & $\mathbf{x}$ & & $\mathbf{x}$ & & & & & & \\
\hline Pau ferro & Caesalpinia ferrea Mart. & Leguminosae & $\mathbf{x}$ & & & & $\mathbf{x}$ & & & & & \\
\hline Pereiro & Aspidosperma pyrifolium Mart. & Apocynaceae & $\mathbf{x}$ & $\mathbf{x}$ & $\mathbf{x}$ & $\mathbf{x}$ & $\mathbf{x}$ & $\mathbf{x}$ & $\mathbf{x}$ & $\mathbf{x}$ & & $\mathbf{x}$ \\
\hline $\begin{array}{c}\text { Pinhão } \\
\text { Pinhão-bravo* }\end{array}$ & Jatropha molissima (Pohl.) Baill. & Euphorbiaceae & $\mathbf{x}$ & $\mathbf{x}$ & $\mathbf{x}$ & $\mathbf{x}$ & $\mathbf{x}$ & $\mathbf{x}$ & $\mathbf{x}$ & $\mathbf{x}$ & $\mathbf{x}$ & $\mathbf{x}$ \\
\hline Quebra-faca & Cássia trachypus Mart. & Leguminosae & $\mathbf{x}$ & & $\mathbf{x}$ & $\mathbf{x}$ & $\mathbf{x}$ & & & & & \\
\hline Quebra-faca** & Crotoncon duplicatus Kunth & Euphorbiaceae & & & & & & $\mathbf{x}$ & & & $\mathbf{x}$ & \\
\hline Quipá & Opuntia inamoena K. Shum & Cactáceae & & & & & & $\mathbf{x}$ & $\mathbf{x}$ & $\mathbf{x}$ & $\mathbf{x}$ & $\mathbf{x}$ \\
\hline Rompe gibão & Mimosa sp. & Leguminosae & $\mathbf{x}$ & & & $\mathbf{x}$ & $\mathbf{x}$ & & & & & \\
\hline Rompe gibão** & $\begin{array}{c}\text { Sideroxylon obtusifolium (Roem. \&Schult.) } \\
\text { Pennington }\end{array}$ & Sapotaceae & & & & & & $\mathbf{x}$ & & & $\mathbf{x}$ & \\
\hline Sabiá & Mimosa caesalpiniaefolia Benth. & Leguminosae & $\mathbf{x}$ & $\mathbf{x}$ & & $\mathbf{x}$ & $\mathbf{x}$ & & & & & \\
\hline $\begin{array}{l}\text { Umburana-de- } \\
\text { cambão }\end{array}$ & Bursera leptophloeos Mart. & Burseraceae & & & & & & $\mathbf{x}$ & & $\mathbf{x}$ & $\mathbf{x}$ & $\mathbf{x}$ \\
\hline Umbuzeiro & Spondias tuberosa Arruda & Anacardiaceae & & & & & & $\mathbf{x}$ & & & $\mathbf{x}$ & \\
\hline Velame & Cróton $\mathrm{sp}$. & Euphorbiaceae & $\mathbf{x}$ & & & & $\mathbf{x}$ & & & & & \\
\hline Velame** & Croton campestri - St. Hilai & Euphorbiaceae & & & & & & $\mathbf{x}$ & & & & $\mathbf{x}$ \\
\hline Xique-xique & Pilosocereus gounellei Weber & & $\mathbf{x}$ & $\mathbf{x}$ & & $\mathbf{x}$ & $\mathbf{x}$ & $\mathbf{x}$ & $\mathbf{x}$ & $\mathbf{x}$ & & \\
\hline \multicolumn{13}{|c|}{ TOTAL } \\
\hline & Espécies: 51 & Família: 19 & 38 & 19 & 13 & 21 & 35 & 23 & 8 & 8 & 12 & 14 \\
\hline
\end{tabular}

Onde: N1= Núcleo de desertificação Cipó/Carrapateiras; N2= Núcleo de desertificação Itacuruba/Tamanduá;

d.s.a $=$ depressão sertaneja aplainada; d.s.d $=$ depressão sertaneja dissecada; $\mathbf{c} . \mathbf{r}=$ cristas residuais;

p.f = planície fluvial; * da mesma espécie com nome popular diferente; ** espécie diferente com mesmo nome popular.

O quadro acima, ainda mostra o número e a distribuição dessas espécies a nível de sistema ambiental. No núcleo Cipó/Carrapateiras foram constatados para a depressão sertaneja aplainada 19 espécies, em contraponto ao mesmo tipo de sistema situado no núcleo de Itacuruba/Tamanduá, com apenas 8. Dentre as espécies apenas 5 são comuns aos sistemas, sendo elas: Caesalpinia pyramidalis Tul. (Catingueira); Cnidoscolus phyllacanthus (Muell. Arg.) Pax\& K. Hoffm. (Favela); o Aspidosperma pyrifolium Mart. (Pereiro); Jatropha molissima (Pohl.) Baill (Pinhão-bravo*) e o Pilosocereus gounellei Weber (Xique-xique).

Isso reflete a diversidade dos sistemas semiáridos em seus aspectos naturais e, sociais quanto aos diferentes usos e ocupações. Os quadros 4 e 5 trazem uma síntese das principais características de cada sistema ambiental, onde podemos observar para este sistema, que apesar de haver uma certa 
aproximação dos fatores naturais e sociais como relevo suave ondulado, solos com características de perfis rasos e pedregosos com maiores atuações dos processos intempéricos, atividades voltadas para a agropecuárias, são de fato os níveis de pressões dessas atividades humanas desenvolvidos nessas condições naturais que variam. Daí a justificativa do primeiro sistema apresentar uma vegetação não só arbustiva e herbácea como também de caatinga arbórea aberta, enquanto o segundo apresenta apenas uma vegetação arbustiva aberta e degradada.

Isso também explica a baixa biodiversidade verificada para a depressão sertaneja dissecada, cuja foram constadas 13 e 8 espécies para o núcleo Cipó/Carrapateiras e Itacuruba/Tamanduá respectivamente, sendo, porém, as quatro primeiras do sistema anterior as únicas espécies em comum.

As cristas residuais apresentaram 21 e 12 espécies para o núcleo cearense e pernambucano, respectivamente. Foram encontradas 6 espécies em comum: Anadenanthera colubrina (Vell.) Brenan. (Angico); Myracroduon urundeuva Fr. All. (Aroeira); Caesalpinia pyramidalis Tul. (Catingueira); Cnidoscolus phyllacanthus (Muell. Arg.) Pax\& K. Hoffm. (Favela); Cereus jamacaru DC. (Mandacaru); e o Jatropha molissima (Pohl.) Baill. (Pinhão-bravo **).

No que diz respeito a esses dois sistemas, há um ponto a se considerar. A primeira área no núcleo de Cipó/Carrapateiras, apesar de se encontrar numa em uma situação de vulnerabilidade ambiental alta, a mesma foi submetida a um estado de pousio, onde a caatinga está em recuperação natural. Ao contrário do que se pode observer nas cristas residuais do núcleo de Itacuruba/Tamanduá, cujo há o desenvolvimento da pecuaria extensiva de modo que vem intensificando a degradação da vegetação. Conforme Sousa (2014), os animais provocam o ramoneamento das cascas das árvores, dos brotos em germinação, dos ramos e das plântulas, acarretando assim o nanonismo, a morte e o aumento dos espaçamento entre os indivíduos.

Quadro 4- Sistemas ambientais do núcleo de desertificação de Cipó/Carrapateiras. Fonte: Trigueiro (2003); Gonçalves (2003). Adaptado pelos autores, 2016.

\begin{tabular}{c|c|c|c|c|c}
\hline $\begin{array}{c}\text { Sistemas } \\
\text { ambientais }\end{array}$ & $\begin{array}{c}\text { Geologia e } \\
\text { Geomorfologia }\end{array}$ & Solo & Vegetação & Atividades & Problemas ambientais \\
\hline
\end{tabular}




\begin{tabular}{|c|c|c|c|c|c|}
\hline $\begin{array}{c}\text { Depressão } \\
\text { sertaneja } \\
\text { aplainada. } \\
\text { (Faz. Vázea } \\
\text { Formosa I) }\end{array}$ & $\begin{array}{l}\text { Corresponde a um nível } \\
\text { intermediário entre o setor } \\
\text { mais dissecado e aplai- } \\
\text { nado (planícies aluviais). } \\
\text { Apresenta um modelado } \\
\text { suave ondulado exibindo } \\
\text { sob rocha Gnaisse. Com } \\
\text { superfícies Ligeiramente } \\
\text { rochosa. Ambiente com } \\
\text { transição tendendo a } \\
\text { instabilidade. }\end{array}$ & $\begin{array}{l}\text { Neossolo Litólico } \\
\text { Eutrófico, apresentando } \\
\text { erosão laminar mode- } \\
\text { rada. A atuação dos pro- } \\
\text { cessos intempéricos em } \\
\text { relação aos processos } \\
\text { pedogenéticos atua de } \\
\text { maneira marcante. } O \text { per- } \\
\text { fil do horizonte apre- } \\
\text { senta } 24 \text { cm de espessura, } \\
\text { onde a rocha se apresenta } \\
\text { bastante alterada. Os teo- } \\
\text { res de matéria orgânica são } \\
\text { muito baixos com cer- } \\
\text { ca de } 13,4 \% \text {. Ambiente bem } \\
\text { drenado. }\end{array}$ & $\begin{array}{l}\text { Cobertura } \\
\text { vegetal com } \\
\text { fisionomia de } \\
\text { caatinga } \\
\text { arbórea aberta, } \\
\text { embora se } \\
\text { encontre } \\
\text { também, uma } \\
\text { estratificação } \\
\text { arbustiva e } \\
\text { herbá- } \\
\text { cea, resultante } \\
\text { da sucessão } \\
\text { eco-lógica } \\
\text { secundária. }\end{array}$ & $\begin{array}{l}\text { Extrativismo } \\
\text { vegetal para uso } \\
\text { local de lenha e } \\
\text { confecção de } \\
\text { cerca e estaca. Alé } \\
\text { da prática do } \\
\text { sobrepastoreio. }\end{array}$ & $\begin{array}{l}\text { Encontram-se numa situação de vulnerabilidade } \\
\text { ambiental pela expansão crescente de extrativis- } \\
\text { mo e da pecuária que diminui sua diversidade e } \\
\text { abundância das espécies, favorecendo também a } \\
\text { diminuição da cobertura vegetal. Isso resulta em } \\
\text { uma maior penetração da luz solar no solo, um } \\
\text { maior aquecimento e evapotranspiração. A di- } \\
\text { nuição no adensamento das espécies modifica u- } \\
\text { midade prejudicando as interações clima-planta- } \\
\text { solo e clima-solo tão necessárias no equi líbrio } \\
\text { do ecossistema. O pastoreio aumenta a carga de } \\
\text { herbivoria da comunidade o que determina uma } \\
\text { competição pela fonte alimentar vegetal. Além } \\
\text { de afetar o solo através do pisoteio do gado, o } \\
\text { que provoca sua compactação. A diminui- } \\
\text { ção da umidade prejudica as atividades micro- } \\
\text { biológicas da reciclagem da matéria orgânica. É } \\
\text { constatado a perda de solos, seja em forma de } \\
\text { soluçãa, dispersão ou mais ainda, através do } \\
\text { processo erosivo. A ação desse procesos é oca- } \\
\text { sionada pelo "run off" das águas de escoamento } \\
\text { superficial, cuja atuação é propiciada pela reti- } \\
\text { rada da vegetação original. A sustentabilidade } \\
\text { se apresenta baixa e a vulnerabilidade alta. }\end{array}$ \\
\hline $\begin{array}{c}\text { Depressão } \\
\text { sertaneja } \\
\text { dissecada. } \\
\text { (Faz. } \\
\text { Cahoeiri- } \\
\text { nha do Pai } \\
\text { Senhor) }\end{array}$ & $\begin{array}{l}\text { Apresenta-se em feições } \\
\text { de colinas rasas em relevo } \\
\text { de topografia suave } \\
\text { ondulada desenvolvida } \\
\text { sobre rochas gnaíssicas } \\
\text { bastante intemperizáveis. } \\
\text { Ambiente moderado a } \\
\text { fortemente instável, } \\
\text { indicando uma situação } \\
\text { evidente de desequilibrio. }\end{array}$ & $\begin{array}{c}\text { Neossolos Litólicos } \\
\text { Eutróficos com espessura de } \\
31 \mathrm{~cm} \text {, onde o Horizonte A } \\
\text { apresenta-se erodido e a } \\
\text { rocha alterada com presença } \\
\text { de pontuações brancas } \\
\text { relativas a restos de minerais } \\
\text { (feldspatos) em processo de } \\
\text { decom posição. Os teores de } \\
\text { matéria organica apresentam } \\
\text { valores moderados a baixos, } \\
\text { variando de } 11,5 \% \\
\text { decrescendo para } 5,6 \% \text {. } \\
\text { Apresenta erosão laminar } \\
\text { com sulcus ocasionais. A } \\
\text { área imperfeitamente } \\
\text { drenado, com profundida-de } \\
\text { indeterminado do lençol } \\
\text { freático. }\end{array}$ & $\begin{array}{l}\text { Vegetação de } \\
\text { caatinga } \\
\text { arbóreo- } \\
\text { arbustiva } \\
\text { aberta, } \\
\text { apresentando } \\
\text { uma } \\
\text { estratificação } \\
\text { herbácea, } \\
\text { resultante } \\
\text { da sucessão } \\
\text { secundária. }\end{array}$ & $\begin{array}{c}\text { A atividade agrí- } \\
\text { cola (evidências } \\
\text { de uso, como o } \\
\text { cultivo de milho) } \\
\text { é feita através de } \\
\text { queimadas. Além } \\
\text { do desmatamento, } \\
\text { a mecanização é } \\
\text { inadequada no } \\
\text { solo por adubação } \\
\text { química, sem que } \\
\text { haja o controle de } \\
\text { agrotóxicos. Há } \\
\text { também o extra- } \\
\text { tivismo da ma- } \\
\text { deira, cuja é utili- } \\
\text { zada para lenha e } \\
\text { confecção de } \\
\text { cercas e estacas. } \\
\end{array}$ & $\begin{array}{c}\text { Encontram-se numa situação de vulnerabilidade } \\
\text { ambiental pela expansão crescente do extrativis- } \\
\text { mo e da pecuária. É constatado a perda de solos, } \\
\text { seja em forma de solução, dispersão ou mais } \\
\text { ainda, através do processo erosivo. A ação des- } \\
\text { ses processos é ocasionada pelo "run off", das } \\
\text { águas de escoamento superficial, cuja atuação é } \\
\text { propiciada pela retirada da vegetação original. } \\
\text { Essa área é a mais agravante, pois há a subs- } \\
\text { tituição da vegetação por pastagem, que não re- } \\
\text { cobre totalmente o solo, vindo assim a inten- } \\
\text { sificar o processos de erosão pelas chuvas tor- } \\
\text { renciais na região. Essa retirada de material é } \\
\text { denunciada morfologicamente pela presença de } \\
\text { pequenos sulcos de erosão hídrica mais intensa } \\
\text { que cortam no sentido do declive. Isso reflete a } \\
\text { ação prejudicial da atividade agrícola. A susten- } \\
\text { tabilidade é mais atenuada com diagnóstico de } \\
\text { baixa a muito baixa e a vulnerabilidade consi- } \\
\text { derada alta. }\end{array}$ \\
\hline $\begin{array}{c}\text { Crista } \\
\text { residual } \\
\text { (Serrote } \\
\text { dos Patos) }\end{array}$ & $\begin{array}{l}\text { Relevo moderadamente } \\
\text { dissecado em colinas } \\
\text { onduladas a suave } \\
\text { ondulada. Manifesta-se } \\
\text { sob rochas migmatitícas e } \\
\text { granitos migmatizados do } \\
\text { Complexo Pedra Branca. } \\
\text { Ambiente com transição } \\
\text { tendendo a estabilidade. }\end{array}$ & $\begin{array}{l}\text { Luvissolos associados a } \\
\text { Neossolos litólico. } \\
\text { Apresentam um perfil com } \\
\text { espessura de } 57 \mathrm{~cm} \text { com } \\
\text { valores moderado, cerca de } \\
18,2 \%, \text { de materia orgânica. } \\
\text { Costatada o tipo de rosão é } \\
\text { laminar ligeira. A área é } \\
\text { caracterizada como modera- } \\
\text { mente drenada com pro- } \\
\text { fundidade indeterminado do } \\
\text { lençol freático. } \\
\end{array}$ & $\begin{array}{l}\text { Vegetação de } \\
\text { caatinga } \\
\text { arbóreo } \\
\text { arbustiva, } \\
\text { apresentando } \\
\text { uma } \\
\text { estratificação } \\
\text { herbácea, } \\
\text { resultante da } \\
\text { sucessão } \\
\text { secundária. }\end{array}$ & $\begin{array}{c}\text { Caatinga em } \\
\text { recuperação } \\
\text { natural. }\end{array}$ & $\begin{array}{l}\text { Encontram-se numa situação de vulnerabilidade } \\
\text { ambiental pela expansão crescente do extra- } \\
\text { tivismo e da pecuária nos locais próximos. É } \\
\text { constatado a perda de solos, seja em forma de } \\
\text { solução, dispersão ou mais ainda, através de } \\
\text { processo erosivo. A ação dos processos erosivos } \\
\text { é ocasionada pelo "run off" das águas de es- } \\
\text { coamento superficial, cuja atuação é propiciada } \\
\text { pelaretirada da vegetação original. A susten- } \\
\text { tabilidade apresenta baixa a ligeiramente mo- } \\
\text { derada e a vulnerabilidade de alta a moderada. }\end{array}$ \\
\hline $\begin{array}{l}\text { Planície } \\
\text { Fluvial }\end{array}$ & $\begin{array}{l}\text { As planícies fluviais apre- } \\
\text { sentam alúvios pouco ex- } \\
\text { pressivos, em decorrência } \\
\text { de estarem posicionados } \\
\text { no embasamento crista- } \\
\text { lino. São ambientes for- } \\
\text { mados por acumulações, } \\
\text { decorrentes de açõs flu- } \\
\text { viais, submetidos a inun- } \\
\text { dações em períodos de } \\
\text { chuvas abundantes. São } \\
\text { constituídos por sedi- } \\
\text { mentos areno-argilosos } \\
\text { limitados por níveis esca- } \\
\text { lonados de terraços even- } \\
\text { tualmente mantidos por } \\
\text { cascalhos, denunciando } \\
\text { evidencias que resultam de } \\
\text { uma evolução recente. Is- } \\
\text { so se traduz na ocorrência } \\
\text { de material imaturo de } \\
\text { maior calibre. }\end{array}$ & $\begin{array}{l}\text { Associações de Neossolos } \\
\text { Flúvicos, Planossolos e } \\
\text { Vertissolos. Há ocorrên- } \\
\text { cia de pedregosidade } \\
\text { superficial, sendo solos } \\
\text { muito susceptíveis à erosão. }\end{array}$ & $\begin{array}{c}\text { Cobertura } \\
\text { vegetal com } \\
\text { uma fisionomia } \\
\text { de mata ciliar, } \\
\text { sendo visivel- } \\
\text { mente mais } \\
\text { verde, mesmo } \\
\text { durante a seca, } \\
\text { do quecobertu- } \\
\text { ra vegetal que } \\
\text { reveste os solos } \\
\text { das áreas pró- } \\
\text { ximas. A ve- } \\
\text { getação secun- } \\
\text { dária ali } \\
\text { instalada, } \\
\text { apresenta-se } \\
\text { degradada. }\end{array}$ & $\begin{array}{l}\text { Área utilizada } \\
\text { para pastos e uso } \\
\text { indiscriminado } \\
\text { através da práticas } \\
\text { da extração } \\
\text { vegetal. }\end{array}$ & $\begin{array}{c}\text { As necessidades locais têm provocado o des- } \\
\text { matamento em áreas às margens do leito, oca- } \\
\text { sionando erosão dos solos, assoreamento dos } \\
\text { rios e, conseqüentemente, a diminuição da } \\
\text { biodiversidade. A margem esquerda do rio } \\
\text { apresenta-se mais degradada, com forte indício } \\
\text { de exploração vegetal, as quais são refletidas } \\
\text { pela grande presença de tocos queimados e } \\
\text { rebrotos. }\end{array}$ \\
\hline
\end{tabular}

Quadro 5- Caracterização dos Sistemas ambientais do núcleo de desertificação de Itacuruba/Tamanduá. Fonte: Sousa (2014). Adaptado pelos autores, 2016.

\begin{tabular}{|c|c|c|c|c|c|}
\hline $\begin{array}{c}\text { Sistemas } \\
\text { ambientais }\end{array}$ & Geologia e Geomorfologia & Solo & Vegetação & Atividades & Problemas ambientais \\
\hline
\end{tabular}




\begin{tabular}{|c|c|c|c|c|c|}
\hline $\begin{array}{l}\text { Depressão } \\
\text { sertaneja } \\
\text { aplainada }\end{array}$ & $\begin{array}{l}\text { Superfícies pediplanadas com } \\
\text { embasamento de rochas do } \\
\text { Pré-Cambriano e de relevo } \\
\text { plano e suave-ondulado. } \\
\text { Ambiente de baixa } \\
\text { instabilidade. }\end{array}$ & $\begin{array}{c}\text { Neossolo } \\
\text { Litólico } \\
\text { Neossolo } \\
\text { Regolítico }\end{array}$ & $\begin{array}{c}\text { Caatinga } \\
\text { arbustiva aberta } \\
\text { e degradada. }\end{array}$ & $\begin{array}{l}\text { Pecuária } \\
\text { extensiva e } \\
\text { agricultura } \\
\text { irrigada. }\end{array}$ & $\begin{array}{l}\text { Vegetação degrada com baixa diver- } \\
\text { sidade floristica; a atividade de sobre- } \\
\text { pastoreio tem provocado ramoneamento } \\
\text { das cascas dasárvores, dos brotos em ger- } \\
\text { minação nos ramos e nas plântulas acar- } \\
\text { retando o nanonismo, morte e aumento } \\
\text { dos espaçamento entre os indivíduos; so- } \\
\text { los erodidos; superfície com cerca de } \\
15 \% \text { a } 50 \% \text { de pedregosidade. }\end{array}$ \\
\hline $\begin{array}{c}\text { Depressão } \\
\text { sertaneja } \\
\text { parcialment } \\
\text { e dissecada }\end{array}$ & $\begin{array}{l}\text { Superfície de erosão, com } \\
\text { embasamento de rochas do } \\
\text { Pré-Cambriano e relevo } \\
\text { ondulado. Ambiente de } \\
\text { transição tendendo à } \\
\text { instabilidade. }\end{array}$ & $\begin{array}{c}\text { Luvissolo } \\
\text { Neossolo } \\
\text { Litólico. }\end{array}$ & $\begin{array}{c}\text { Caatinga } \\
\text { arbustiva aberta } \\
\text { degradada. }\end{array}$ & $\begin{array}{c}\text { Pecuária } \\
\text { extensiva. }\end{array}$ & $\begin{array}{l}\text { Vegetação degradada; A atividade de } \\
\text { sobrepastoreio tem provocado ramonea- } \\
\text { mento das cascas dasárvores, dos brotos } \\
\text { em germinação nos ramos e nas plântulas } \\
\text { acarretando o nanonismo, morte e au- } \\
\text { mento dos espaçamento entre os indiví- } \\
\text { duos; solos erodiso com pedregosidade. }\end{array}$ \\
\hline $\begin{array}{c}\text { Crista } \\
\text { residual. }\end{array}$ & $\begin{array}{l}\text { Relevo dissecado com } \\
\text { interflúvios culminando em } \\
\text { cristas, rochas do Pré- } \\
\text { Cambriano; relevo forte } \\
\text { ondulado a montanhoso. } \\
\text { Ambiente de transição } \\
\text { tendendo à instabilidade. }\end{array}$ & $\begin{array}{l}\text { Neossolo } \\
\text { Litólico. }\end{array}$ & $\begin{array}{c}\text { Caatinga } \\
\text { arbustiva aberta } \\
\text { e degradada }\end{array}$ & $\begin{array}{l}\text { Pecuária } \\
\text { extensiva }\end{array}$ & $\begin{array}{l}\text { Vegetação degrada; a atividade de } \\
\text { sobrepastoreio tem provocado } \\
\text { ramoneamento das cascas dasárvores, } \\
\text { dos brotos em germinação nos ramos e } \\
\text { nas plântulas acarretando o nanonismo, } \\
\text { morte e aumento dos espaçamento entre } \\
\text { os indivíduos; pedregosidade sobressai } \\
\text { na paisagem variando de } 50 \% \text { a } 100 \% \\
\end{array}$ \\
\hline $\begin{array}{l}\text { Planícies } \\
\text { fluviais }\end{array}$ & $\begin{array}{l}\text { Áreas planas resultantes da } \\
\text { acumulação fluvial de } \\
\text { sedimentos: cascalhos, areia } \\
\text { fina e grossa e argila. } \\
\text { Ambiente de transição } \\
\text { tendendo a instabilidade. }\end{array}$ & $\begin{array}{c}\text { Neossolo } \\
\text { Flúvico. }\end{array}$ & $\begin{array}{l}\text { Caatinga } \\
\text { arbórea- } \\
\text { arbustiva }\end{array}$ & Área preservada & Não discriminado \\
\hline
\end{tabular}

No sistema de planície fluvial do núcleo Cipó/Carrapateiras, foram encontradas 35 espécies de um total de 38 para toda área, fato este que a destaca como o sistema de maior diversidade. O mesmo ocorre com a planície fluvial do núcleo de Itacuruba/Tamanduá, onde foram encontradas 14 espécies. As espécies em comum são: Caesalpinia pyramidalis Tul. (Catingueira); Cnidoscolus phyllacanthus (Muell. Arg.) Pax\& K. Hoffm. (Favela); Caesalpinia ferrea Mart. (Jucá); Pithecellobium diversifolium Benth (Jurema Branca); Aspidosperma pyrifolium Mart. (pereiro) e Jatropha molissima (Pohl.) Baill (Pinhão-bravo**).

Observa-se que acontece o contrário do que ocorre no sistema ambiental anterior. A primeira plánície por situar no alto curso do rio Jaguaribe, apresenta um desenvolvimento pouco expressivo, no que diz respeito aos seus depositos aluviais além de solos suceptível a erosão. Associado a isso verifica-se o uso indiscriminado de seus recursos naturais, através da prática da extração vegetal e sobrepastoreio, porém, dentre os sistemas ambientais analisados é a mais rica em diversidade florística.

A segunda planície, da sub-bacia do riacho Itacuruba/Tamanduá, encontra-se situada na macrobacia do rio São Francisco. Apesar de se constituir em uma área geomorfologicamente plana com depósitos aluviais mais profundos, e além disso, atualmente se encontrar em estado de preservação, a mesma não garante a presença de uma grande diversidade florística.

Tal realidade pode ser explicada pela investigação dos usos outrora realizado nesse sistema, cujo os efeitos ainda perduram no ambiente. Ainda mais quando se trata da bacia do rio São Francisco, cuja foi historicamente explorada pela atividade criatória, na qual teve como meio a retirada da vegetação para a instalação de fazendas e pastos. 


\section{CONSIDERAÇÕES FINAIS}

A partir dessas análises pode-se diagnóticar um total de 51 espécies e 19 famílias para os núcleos da sub-bacia do Cipó-Carrapateiras e de Itacuruba/Tamanduá. Levando em consideração cada núcleo, se obteve um valor de 38 especies e 14 famílias e 23 espécies e 12 famílias para o núcleo cearense e pernambucano respectivamente.

$\mathrm{Na}$ dimensão dos sistemas ambientais foram constatados que as planícies fluviais são as que apresentam maiores diversidades, onde foram encontratadas 34 espécies para a planície situda no núcleo cearense e 14 espécies para planície do núcleo pernambucano. Já os sistemas de menor diversidade foram para o núcleo Cipó/Carrapateira a depressão sertaneja dissecada com apenas 13 espécies, seguida da depressão sertaneja aplainada e dissecada do núcleo de Itacuruba/Tamanduá com 8 espécies cada um. Podemos concluir que o núcleo cearense apresenta maior diversidade florística, o que não significa necessariamente afirmar que o mesmo esteja sendo preservado.

\section{REFERÊNCIAS}

CEARÁ. Secretaria de Recursos Hídricos, Programa de Ação Estadual de Combate à Desertificação e Mitigação dos Efeitos da Seca, PAE-CE. Fortaleza: Ministério do Meio Ambiente / Secretaria dos Recursos Hídricos, 2010. $375 p$.

GONÇALVES, A. M. Estudo do Ecossistema da Mata Ciliar nas Sub-bacias dos Riachos Cipó e Carrapateiras: Tauá - CE. Dissertação (Mestrado em desenvolvimento e meio ambiente)- Centro de Ciências, Universidade Federal do Ceará, Fortaleza, 2003. 180p.

LEAL, I. R; TABARELLI, M; SILVA, J. M. C. 2003. Introdução. Ecologia e conservação da Caatinga: uma introdução ao desafio. In: Ecologia e conservação. Ecologia e Conservação da Caatinga. Recife: Ed. Universitária da UFPE, 2003, p. XIII- XVI. Disponível em:

<http://s3.amazonaws.com/academia.edu.documents/44593309/5_livro_ecologia_e_conservao_da_caatinga_203.pdf?A WSAccessKeyId=AKIAJ56TQJRTWSMTNPEA\&Expires=1471188463\&Signature=zPtsD5WXtWTOwQdu6eFl1gzO UIg\%3D\&response-content disposition=inline\%3B\%20filename\%3DEcologia_e_Conservacao_da_Caatinga.pdf $>$. Acesso em: 14/08/2016.

Ministério do Meio Ambiente - MMA. Bioma Caatinga. 201-. Disponível em:

<http://www.mma.gov.br/biomas/caatinga> Acesso em: 14/08/2016.

PERNAMBUCO. Secretaria de Ciência, Tecnologia e Meio Ambiente. Programa de Ação Estadual de Pernambuco para o Combate à Desertificação e Mitigação aos Efeitos da Seca, PAE-PE. Recife: CEPE, 2009. 96p.

SOUSA, S. C. Avaliação da Degradação/desertificação causada pelo uso e ocupação do solo dos rios São Francisco e Jaguaribe no semiárido nordestino: propostas de recuperação. Tese (Doutorado em Desenvolvimento e Meio ambiente)- Centro de Ciências, Universidade Federal do Ceará, Fortaleza, Fortaleza, 2014. 206p.

TRIGUEIRO, E. R. C. Vulnerabilidade aos processos de degradação/desertificação no município de Tauá-Ce. Estudo de caso: Escola Agrícola de Tauá. Dissertação (Mestrado em desenvolvimento e meio ambiente) - Centro de Ciências, Universidade Federal do Ceará, Fortaleza, 2003. 126p. 


\section{AGRADECIMENTOS}

Ao Conselho Nacional de Desenvolvimento Científico e Tecnológico - CNPq pelo apoio no desenvolvimento dessa pesquisa.

Recebido em: 14/08/2016

Aceito para publicação: 01/10/2016 